Escuela de Ciencias Sociales y Humanidades, UNED, C.R.

URL: http://investiga.uned.ac.cr/revistas/index.php/espiga/index

DOI: http://dx.doi.org/10.22458/re.v16i33.1767

ISSN: $1409-4002 \cdot$ e-ISSN: 2215-454X

\title{
La criminalidad como tema historiográfico: Chile en el siglo XIX
}

\author{
Juan Guillermo Estay-Sepúlveda* \\ Alessandro Monteverde-Sánchez**
}

Recibido: 02 de junio, 2016 - Aceptado: 28 de junio, 2016 - Corregido: 15 de marzo, 2017

RESUMEN

La problemática de la criminología ha sido indagada por diversos historiadores a través del tiempo. Sin embargo, se ha encontrado con la carencia de falta de respuestas la cual ha sido suplida por estudios generales de acontecimientos y aproximaciones temáticas. Lo que se presenta es una tratativa de llenar un vacío con trabajos de significación, que al analizarlos cubren esta falencia en parte, y ayudan a entender el trabajo individual de varios investigadores, quienes han sistematizado una problemática. Se trata de una problemática recurrente y discursiva en la actualidad, la cual periódicamente se cubre de nuevas y valiosas interpretaciones. Al analizar las obras de los historiadores que han ingresado a la temática de la criminalidad y la criminología, queremos ser un aporte sustancial para desvelar nuevas interpretaciones y crear nuevo conocimiento.

Palabras clave: Criminalidad - Élites - Chile - Control Social - Siglo XIX

\section{Formato de citación según APA}

Estay-Sepúlveda, J.G., y Monteverde-Sánchez, A. (2017). La criminalidad como tema historiográfico: Chile en el siglo XIX. Revista Espiga, 16(33), 131-147. DOI: http:// dx.doi.org/10.22458/re.v16i33.1767

Formato de citación según Chicago

Estay-Sepúlveda, Juan Guillermo y Alessandro Monteverde-Sánchez. «La criminalidad como tema historiográfico: Chile en el siglo XIX». Revista Espiga, 33 (2017): 131147. DOI: http://dx.doi.org/10.22458/re.v16i33.1767

* Universidad de Los Lagos, Chile. Profesor de Historia y Geografía. Doctorando en Historia. Investigador Centro Studi Sea, Italia e Investigador Cátedra Hermenéutica Campus Soria Universidad de Valladolid, España. Editor Revista Pasajes Universidad Nacional Autónoma de México. Chile. juanguillermoestay@yahoo.es

** Universidad de Playa Ancha, Chile. Profesor de Historia y Geografía. Magíster en Historia. Investigador Departamento de Historia Universidad de Playa Ancha y Profesor Asociado de la misma Casa de Estudios Superiores. Chile. amontev@gmail.com 
Soy partidario de la pena de muerte inmediata, sobrecaliente, de cogoteros y de asesinos cobardes. No soy partidario de aplicar la pena de muerte al que sufrió una larga pena de cárcel. Estoy seguro de que el peor asesino, después de un año de suplicio en una celda, no es el mismo que asesinó. En cada ser humano hay posibilidades de metamorfosis. La pena de muerte se presta a no pocas hipocresías. Las dudas en este sentido son espantosas. No sabemos si el dolor ajeno nos produce placer o dolor. No confesaríamos nunca la verdad

\section{Introducción}

La revisión historiográfica de la criminalidad y sus resultados en el Chile decimonónico conlleva el conocimiento de un aparataje importante de archivos, libros, revistas, tesis de postgrado y otros documentos que den luces para adentrarse en esta temática. Se reconoce que, día a día, se suman más investigadores a esta incansable labor. Sin embargo, hay que señalar que las vertientes de interpretación, uso, interés o aproximación al tema, puede producir deslizamientos en ciertas tendencias o gustos. Además, estarían más cercanas o lejanas a los intereses personales, que permanentemente salen a relucir y, sobre todo, cuando hay cuestiones de objetividad y definición de por medio.

La historia, como la justica, a veces olvida su venda de compresión del binomio pasado-presente/presente-pasado y la levanta con su otra mano ocupada, para mirar y hacer sus juicios valóricos. Entonces y por lo antes expuesto, el enfoque no pasa por lo ideológico, sobre todo en lo que se refiere a abrazar una escuela en desmedro de otra o para entrar en una competencia doctrinaria, la cual cree no corresponde.

\section{Antecedentes teóricos de la criminalidad}

Hay numerosas definiciones sobre criminalidad, pero este estudio ha optado por las definiciones de Hermann Mannheim y Émile Durkheim. Mannheim, define el crimen desde el punto de vista jurídico, donde todo comportamiento humano -acción u omisión- será previsto y castigado por la ley penal por causa del trastorno ocasionado al orden social. Sin embargo, el concepto legal encubre una realidad humana y social como fenómeno, la cual es anterior a la ley y a quien la motiva. Efectivamente, en cada delito $^{2}$ se encuentra el acto de un individuo en rebelión contra su sociedad. Durkheim define el delito como un fenómeno normal, donde no se puede concebir una sociedad que esté completamente libre de él (es necesario), pues el delito está vinculado a las condiciones fundamentales de cualquier vida social (es útil); asimismo, las condiciones de las que es solidario son las mismas indispensables a la evolución normal de la moral y del derecho. Para Durkheim, el delito es una noción eminentemente social, es decir, esencialmente relativa. ${ }^{3}$

1. Joaquín Edwards Bello, Andando por Madrid y otras páginas (Santiago: Editorial Andrés Bello, 1969), 152-153.

2. Ocupamos el concepto delito, tal como lo analiza Beccaria en forma y fondo. Recordemos que la obra culmine del autor se denomina «De los delitos y las penas». Seguiremos en este artículo la misma línea histórico-filosófica.

3. José María Rico, Crimen y justicia en América Latina, (México: Editorial Siglo XXI, 1981), 38-39. 
Efectivamente, no existe ningún acto que sea, por sí mismo, un crimen, por más grave que sean los daños ocasionados. Su autor sólo será considerado como criminal si la opinión común del grupo social al que pertenece lo trata como tal. Por otra parte, Máximo Paverini, expuso acerca del concepto de desviación, elemento fundamental al tramado criminal. El autor señala que la formación eminentemente sociológica de los criminólogos estadounidenses puede explicar en parte la confianza hacia un término -el criminal- tan comprometido con un explícito juicio de valor y, sobre todo, tan anclado únicamente al parámetro legal: el concepto de desviación se presenta, por el contrario, con los atributos de una aparente neutralidad y con una intrínseca potencialidad de re-comprender, tanto los fenómenos más diversos, como la pluralidad de parámetros capaces de calificar un determinado comportamiento.

En otras palabras, desviación sirve para abrazar, egregiamente y de manera unitaria, los diversos problemas de malestar social y de no integración ${ }^{4}$. No es posible dudar sobre la mayor elasticidad y ductilidad del concepto de desviación, al encontrar fundadas perplejidades que surgen a propósito de la presunta neutralidad de este término y, en particular, de su afirmada no normalidad. Esto es posible pese a lo muy diversas y a veces opuestas de las justificaciones teóricas de su utilización en criminología. De este concepto, desviado puede ser sólo quien se califica negativamente respecto de una norma, en distintas formas. ${ }^{5}$

Considerando lo antes expuesto, el propósito aquí no es discutir aspectos teóricos ${ }^{6}$ de la criminología ni sus distintas escuelas, ni profundizar la temática del derecho penal y sus distintas tendencias y escuelas, las cuales han definido y conceptualizado las distintas posturas de la criminología ${ }^{7}$, sino pasar revista a como ha sido vista la criminalidad en el siglo XIX por los historiadores chilenos, cuando el país comenzaba su vida emancipadora y se consolidaba en la República.

\section{Antecedentes históricos de la criminalidad}

Desde el nacimiento de la humanidad, las sociedades se han organizado estableciendo normas de comportamiento entre sus integrantes. Estos acuerdos pueden tener carácter social, religioso, ético, moral o penal y se interpretarán como un pacto, un acuerdo entre cada individuo y el grupo social al que pertenece. Según esto, la violación a éste pacto es considerado -desde la antigüedad-como una anomalía o una anormalidad, que

4. Michel Foucault, La vida de los hombres infames (Buenos Aires: Editorial Altamira, 1996).

5. Massimo Pavarini, Control y dominación: Teorías criminológicasburguesas y proyecto hegemónico (México: Editorial Siglo XXI, 2003). Un nuevo concepto va a reemplazar al delincuente, al loco o al pobre: el de desviado, 62-63.

6. Juan Pablo Mollo, Psicoanálisis y criminología. Estudios sobre la delincuencia (Buenos Aires: Editorial Paidos, 2010), diríjase principalmente la segunda parte del texto; Rosa del Olmo, América Latina y su criminología (México: Editorial Siglo XXI, 1987) y Ricardo D. Salvatore, Subalternos, derechos y justicia penal (Barcelona: Editorial Gedisa S.A., 2010).

7. $\mathrm{Al}$ respecto, ver entre otros a Manuel de Rivacoba, Violencia y Justicia (Valparaíso: Editorial Universidad de Valparaíso, 2002); Manuel López-Rey y Arrojo, La criminalidad. Un estudio analítico (Madrid: Editorial Tecnos, 1976) y Las dimensiones de la Criminalidad (Córdoba: Editorial Marcos Lerner, 1987); Alfonso Serrano Maillo, Introducción a la criminología (Madrid: Editorial Dykinson, 2009) y Fernando Gil Villa, La delincuencia y su circunstancia: sociología del crimen y la desviación (Valencia: Editorial Tirant lo Blanch, 2004). 
debe ser prontamente castigada. Esto evita que «él o los» quebradores de la normativa vuelvan a incurrir en el ilícito. o que otros imiten esa acción, la cual se puede transformar en un mal ejemplo. Con ello, se comienza a configurar y consignar que este tipo de actos y acciones, sean controlados, castigados o reprimidos, por las autoridades o por las personas comunes que componen la comunidad ${ }^{8}$. El castigo y la pena de muerte estarían, de este modo, presentes en la todas las sociedades, las cuales tendrían su propia visión al respecto 9 .

Ahora bien, la pena máxima no ocurría en forma instantánea. El condenado era entregado a la justicia para purgar el delito o crimen. Purga en la cual el ingenio humano no quedó atrás al crear innumerables sistemas, métodos y herramientas de tortura ${ }^{10}$. Lo anterior no dejó inmune a parte importante de la sociedad, como a Beccaria ${ }^{11}$, quien criticará severamente el método de tortura como infame e inútil. César Beccaria no estará solo en la cruzada y un gran número de pensadores de la Ilustración se horrorizarán frente al espectáculo de la tortura y sus métodos y levantarán su voz. Estos pensamientos llegarán a los habitantes de las nuevas repúblicas latinoamericanas, las cuales comenzaban su viaje en el mundo de la vida civilizada. Por consiguiente, dejaban tras sí una época colonial que no acaba con la emancipación, sino que se proyectaría en el tiempo, ${ }^{12}$ según las características de cada uno de los nuevos Estados latinoamericanos, pese a que su intelectualidad era asidua visitante de Europa y los Estados Unidos y observaba lo ocurrido en esas latitudes y que sería analizado por los historiadores sociales del siglo XX en materia histórica y teórica ${ }^{13}$.

\section{La visión legislativa en la época Colonial}

Las características generales y dominantes de este período pasan por la escasa consideración otorgada en materia de libertad a los aborígenes y criollos, a pesar de ciertas leyes de protección y distintos conceptos políticos emanados desde la metrópolis.

Por otro lado, la Recopilación de Leyes de Indias adopta ciertas penas y tiene en consideración algunas costumbres ancestrales de los pueblos originarios sometidos. Esas

8. Bronislaw Malinowski, Crimen y costumbre en la sociedad salvaje (Barcelona: Editorial Ariel, 1971).

9. Véase entre otros a Jean Imbert, La Pena de Muerte (México: Editorial Fondo de Cultura Económica, 1993); Agustín Basave Fernández del Valle, Meditación sobre lapena de muerte (México: Editorial Fondo de Cultura Económica, 1997); Daniel Sueiro, La pena de muerte (Madrid: Alianza Editorial, 1974); Richard Quinney, Clases, Estado y Delincuencia (México: Editorial Fondo de Cultura Económica, 1985) y Nils Christie, Los límites del Dolor (México: Editorial Fondo de Cultura Económica, 1984).

10. Michael Foucault, Sorvegliare e punire. Nascita de lla prigione (Torino: Editorial Giulio Einaudi Editores, 1976). En lengua castellana: Vigilar y castigar. Nacimiento de la prisión (Buenos Aires: Editorial Siglo XXI, 2002).

11. Cesare Beccaria, De los delitos y de las penas (Madrid: Alianza Editorial, 1968).

12. Por ejemplo, el Código Civil de Chile data de 1856 y el Código Penal de 1874 . Antes de estos códigos se seguía legislando con la normativa jurídica colonial.

13. Howard Zehr, Crime and the development of modern society (Guildford: Editorial Biddles Ltd., 1976); Nicole Castan, Justice et repression en Languedoc a l'epoque des Lumieres (Paris: Editorial Llamerion, 1980); Umberto Levra, La scienza e la colpa. Crimini, criminali, criminología. Un voltodell' ottocento (Milano: Editorial Electra, 1985);Oscar Di Simplico, La criminalitáa Siena. (1551-1808) (Bolonia: Quaderni Storici № 49, Editorial Il Molino, 1982); Fernando Álvarez Uría, Miserables y Locos, (Madrid: Editorial Tusquets, 1983); José Luis Peset, Ciencia y marginación (Madrid: Editorial Crítica, 1983); entre otros. 
costumbres combinadas con las hispanas, van dando cuerpo a la reglamentación penal. Según José María Rico, ${ }^{14}$ existen penas en materia de homicidios, lesiones, duelos, injurias, robo, abigeato, adulterio, violación, sodomía, concubinato, entre otros.

Cobra importancia ante este tópico, las palabras de William Taylor ${ }^{15}$, quien pone de manifiesto la relevancia del tema social al referirse al Virreinato de Nueva España. Critica permanentemente a aquellos poseedores del poder político, económico y religioso, quienes dejan de lado a una parte importante de la población como los campesinos y a la población urbana de las clases humildes. A partir de esta posición, Taylor se refiere a los distintos tipos de documentos archivísticos que analizó, la mayoría de los cuales fueron escritos por la élite para sus propios fines. Muchas de estas fuentes son sobre campesinos, las cuales no se encuentran escritas por sus verdaderos protagonistas. Para el presente tema, el historiador se ha apoyado en actas de juicios, donde se detallan distintos actos ilegales, descripciones de los delitos y declaraciones de acusados y acusadores. La situación no cambia para el resto del continente y se encuentra la voz del que no tiene voz en los archivos Según sus palabras, que no son sus palabras, ya que es guiado en su interrogatorio y lo que piensa la élite peninsular y, posteriormente, la criolla queda sobre papel el modelo de Hobsbawn ${ }^{16}$, muchas veces, no es aplicable a esta parte del mundo. El Robín Hood, la protesta social, el precapitalismo deben tener en consideración el tiempo y el espacio. América Latina y Chile, en particular, no es el Mediterráneo donde el Hobsbawn instala su bandido.

\section{Marco histórico general de América Latina a comienzos del siglo XIX}

Se ha planteado que no es posible hacer tabla rasa entre el período colonial y el período republicano de los Estados Latinoamericanos. La firma del acta de independencia de Chile (el 12 de febrero de 1818), de la Gran Colombia (el 17 de diciembre de 1819) o México (el 28 de septiembre de 1821) no significaba que el día 19 de febrero, 18 de diciembre y 29 de septiembre todos los habitantes e instituciones de los nuevos países americanos comenzaran a pensar y obrar distinto. Sin embargo, se produjo un período de inestabilidad política por motivos acomodaticios de las élites criollas, debido principalmente a las crisis económicas causadas por las guerras emancipadoras. Consecuentemente, estas guerras redundaron en una etapa de virulencia social. Con esta problemática en ciernes, Latinoamérica retrasó los procesos de formación, organización y desarrollo de la nación. ${ }^{17}$ Esta situación provocó que una gran cantidad de personas se vieran involucradas

14. José María Rico, Crimen y justicia en América Latina. (México: Editorial Siglo XXI, 1981).

15. William Taylor, "Algunos temas de la historia social de México en las Actas de juicios criminales», Revista Relaciones Estudios de Historia y Sociedad no 11: (1982), http://etzakutarakua.colmich.edu.mx/relaciones/011/ pdf/WilliamTaylor.pdf consultada con fecha 07 de mayo de 2014.

16. Eric Hobsbawm, I Rebelli. Forme primitive di rivolta sociale (Torino: Giulio Einaudi Editores, 1974). En lengua castellana: Rebeldes primitivos: Estudio sobre las formas arcaicas de los movimientos sociales en los siglos XIX y XX (Barcelona: Editorial Crítica, 2001), I banditi. Il bantitismo social en ell' etá moderna (Torino: Giulio Enaudi Editores, 1971). En lengua castellana: Bandidos (Barcelona: Editorial Crítica, 2001).

17. Al respecto ver John Lynch, Los factores estructurales de la crisis: la crisis del orden Colonial,en Historia General de América Latina (Madrid: Editorial UNESCO/Editorial Trotta, Tomo V, 2003), 31-54; Miguel Chust Caleno, La coyuntura de la crisis: España, América, en Historia General de América Latina (Madrid: Editorial UNESCO/Editorial Trotta, Tomo V, 2003), 55-85; Nelson Manríquez, Las sociedades originarias en el ámbito 
en distintas situaciones de peligro y provocó impacto en su vida personal, donde algunos fueron víctimas y otros transgresores.

Consecuencia de ello, América post emancipación va a producir un cierto incremento de la delincuencia, sobre todo por el proceso de reorganización e imposición del Estado de Derecho, la aplicación de medidas de contención y control poblacional, a través de las Cartas Fundamentales y también por las distintas medidas de control a los habitantes de estas nuevas naciones que se formaron. Durante las primeras décadas del decimonono, se dio la persecución y violencia política entre el bando triunfador y el bando perdedor ${ }^{18}$, representado en destierros, prisión o simplemente, la eliminación del contrario. Entonces, se crearon formas legales y tribunales encargados de cumplir la ley creada por quien ostentaba el poder. Ahora bien, los de abajo sufrieron la férrea disciplina de las noveles repúblicas. En México, por ejemplo, los léperos -gente empobrecida-, eran quienes desfilaban mayoritariamente en los tribunales de justicia, donde los expedientes criminales nos demuestran que «la mayoría de los delincuentes registrados en este trabajo pertenecían a la llamada clases bajas» ${ }^{19}$.

Estos miserables que pululaban por Ciudad de México, en un número bastante importante, se habían constituido en una real amenaza para el orden establecido, pese a que la mayoría de estos, no tenían un sitio para vivir y mucho menos medios para ganarse el pan de cada día. Súmese a ello, los migrantes desde el mundo rural que venían en las mismas condiciones paupérrimas.

La centralidad que han tenido los textos elaborados por las diferentes instituciones de control social en las estrategias para investigar ha minimizado e incluso ha eliminado la percepción de otros actores en otros procesos. ${ }^{20}$ Los actores, que pertenecen a los

de la formulación inicial de los proyectos nacionales como culminación de los procesos de continuidad y ruptura, en Historia General de América Latina (Madrid: Editorial UNESCO/Editorial Trotta, Tomo V, 2003) 351364; John V. Lombardi, Independenciay esclavitud en el períodode transición de 1750-1850, Historia General de América Latina (Madrid: Editorial UNESCO/Editorial Trotta, Tomo V, 2003), 365-382; José Chiaramente y Nora Souto, De la ciudad a la nación. Las vicisitudes de la organización política Argentina y los fundamentos de la conciencia nacional, en Relatos de nación. La construcción delas identidades nacionales en el mundo hispánicoTomo I (Madrid: Instituto de Filosofía Consejo Superior deInvestigaciones Científicas/Organización de Estados Americanos para la Educación, la Ciencia y la Cultura, 2005) 311-332;Véase también entre otros a Hilda Sábato, Ciudadanía Política y Formación de naciones. Perspectivas históricas de América Latina (México: Editorial Fondo de Cultura Económica/El Colegio de México, 1999); John Lynch, América Latina entrela Colonia y Nación (Barcelona: Editorial Crítica, 2001) y Tulio Halperin Donghi (compilador) El ocaso del ordenColonial en Hispanoamérica (Buenos Aires: Editorial Sudamericana, 1978).

18. Carlos Contreras y Marcos Cueto, Historia del Perú Contemporáneo (Lima: Red para el Desarrollo de las Ciencias Sociales en el Perú, 2000), 37-73; Thomas E. Skidmore y Peter H. Smith, Historia Contemporánea de América Latina (Barcelona: Editorial Crítica, 1996), 42-50; José Luis Romero, Independenza en Storiadell' America Latina (Firenze: La Nuova Italia Editrize, 1979), 162-175; Andrea Slemian y Joao Paulo Pimenta, O Nascimento político do Brasil, as origen do Estado e da nacao (1808-1825) (Río de Janeiro: DP\&A Editora,2003; Marcello Carmagnani, El otro Occidente (México: Editorial Fondo de Cultura Económica/El Colegio de México, 2004) yJohn Lynch. Las Revoluciones Hispanoamericanas 1808-1826 (Barcelona: Editorial Ariel, 2010).

19. Teresa Lozano Armendares, La Criminalidad en la Ciudad de México, 1800-1821 (México: Universidad Nacional Autónoma de México, 1987), 30.

20. María Silvia Di Liscia y Ernesto Bohoslavsky, Instituciones y formas de control social en AméricaLatina, 18401940. Una revisión. (Buenos Aires: Prometeo Libros, 2005), 10. 
ámbitos oficiales de las élites, parecen ser los protagonistas únicos de esta historiografía. Asimismo, se descartan las acciones y la presión que ejercen los sectores oprimidos frente a un sistema implementado desde arriba. Así mismo, aquella historiografía se ha encargado del control social, centralizando su atención en zonas y eventos donde el pensamiento positivista y criminológico había logrado vencer y establecerse, pero sin preocuparse de observar y aceptar los fallos en la cual incurrió o cuando debió modificar o cambiar sus objetivos. Esto ha conllevado a omitir el análisis de aquellos fenómenos acaecidos lejos de las ciudades urbanizadas, en ocasiones muy reiteradas.

\section{Criminalidad y delincuencia en Chile en el siglo XIX: balance historiográfico}

Actualmente, y a cada momento, los medios de comunicación de toda índole bombardean acerca de la delincuencia y temas afines. Claro que hay que mencionarlo a riesgo de recibir críticas - iy qué historiador no las recibe cuando hace una radiografía del presente! y ser preciso en que la manifestación mediática trae consigo motivos políticos de todas las direcciones. Ciertamente, el fenómeno delictivo debiera cuestionarse qué tan responsables son-como sociedades frente a este fenómeno. De igual forma fue la pregunta que posiblemente se formularon los antepasados decimonónicos.

Se trata de un problema de marginación, de falta de oportunidad, postergación, aislamiento y desconsideración dentro de un sistema o forma de actuar y gobernar. Se podría aproximar una idea. Este tipo de situación -la criminalidad-es causa de que muchos niños crezcan en situaciones de riesgo donde el delinquir, en el más amplio sentido de la palabra, es la solución para evitar el hambre y conseguir la sobrevivencia.

Si lo anterior se retrotrae al Chile decimonónico, lógicamente se encontrarían escenarios muy diferentes, pero ciertas directrices parecidas, a saber, la carencia de oportunidades. A partir de los acercamientos expuestos, se revisaron aspectos historiográficos de la conformación del estado de la criminalidad en el siglo XIX. La época en cuestión y principalmente la primera etapa de este estudio (de 1800 a 1850) poseía un orden social, el cual pretendía mantener a la población en un status quo jerarquizado, bajo la consigna del orden republicano. El eje era la figura e impronta que dejara Diego Portales y Palazuelos y la Constitución de $1833^{21}$, donde se busca el bien común, pero sometiendo al más débil y desclasado. Durante el período 1850 a 1900, el país ingresó en una etapa de reformas liberales, las cuales abogaron por la población desposeída, pero bajo el concepto de la filantropía o la instrucción conforme a sus propios cánones.

\section{Período 1800-1850}

El período en cuestión presenta aportes históricos importantes, aunque no son suficientes para esclarecer ciertos tópicos en materia de criminalidad. Aquí este estudio

21. Véase para el caso el análisis que hace del gobierno de los decenios Simon Collier y William Sater, Historia de Chile 1808-1994 (Madrid: Cambridge University Press, 1999). 
se nutre de referencias encontradas en algunas historias generales de Chile ${ }^{22}$ y de otros aportes de la época. Se puede agregar, a lo anterior algunos periódicos como El Monitor Araucano, El Mercurio de Valparaíso o El Ferrocarril como referencia, los cuales entregan comentarios acerca de la situación social en editoriales y opiniones. Al mismo tiempo; en sus noticias, dan un panorama del vivir del bajo pueblo. Se suma a ello, algunos pasquines y panfletos, que aportan noticias y preocupación por lo delictivo. Posteriormente, los historiadores del siglo XX han puesto su atención en resaltar esta realidad social de diferentes escuelas historiográficas, que se han adentrado en la historia de los desposeídos, con sus visiones. ${ }^{23}$

Volviendo a los aspectos teóricos de formación de la República de Chile, cabe resaltar que los estudios de las ideas políticas de esta época ${ }^{24}$ arrojaron como resultado la predominancia de la idea del ordenamiento de la nación. Este elemento le dio un sello de orden legal-institucional durante todo ese siglo y el posterior. De ahí que fuese el Estado, centro de los estudios y preocupación de los historiadores durante mucho tiempo ${ }^{25}$.

Pero a pesar de lo señalado anteriormente, existen ciertas preguntas referidas a lo analizado en este artículo y que Marcelo Neira Navarro, citando a Simon Collier, da la respuesta, al sostener que:

durante la primera mitad del siglo XIX, varias técnicas de coacción se ensayaron sistemáticamente. Junto a la represión destacaron mecanismos de disciplina social como el rol de la iglesia católica, la reorganización y control administrativo (manejo del sistema electoral) y la reorganización de las milicias. Para explicar el caso de la represión, es necesario señalar que ella se vincula a una necesaria reorganización administrativa. Esta permitirá el control político subsecuente. A partir de aquí, se construyó todo un sistema normativo, de control, de represión y por cierto de exclusión. En la sociedad de la época, todo aparece objetivado en la actividad desplegada por el sistema policial-penal. ${ }^{26}$

22. Diego Barros Arena, Historia General de Chile, Vol. VI (Santiago: Editorial Nascimento, 1932); Francisco Antonio Encina, Historia de Chile, Vol. XX (Santiago: Editorial Nascimento, 1947);Luis Galdámes, Historia de Chile (Santiago: Editorial Zig-Zag, 1952);Santiago Lorenzo Schiffino, Origen de las Ciudades Chilenas. Las fundaciones del siglo XVIII (Santiago: Editorial Andrés Bello, 1983); José Toribio Medina, Cosas de la Colonia. Aportes para la crónica del siglo XVIII en Chile, (Santiago: Fondo Histórico y Bibliográfico José Toribio Medina, 1952) y Jaime Eyzaguirre, Historia de Chile (Santiago: Editorial Zig-Zag, 1982).

23. Mario Góngora del Campo, Vagabundaje y Sociedad Fronteriza (Valparaíso: Editorial Jurídica Universidad Católica de Valparaíso, 1980); María Teresa Cobos, «La Institución del Juez del Campo en el reino de Chile durante el siglo XVIII», Revista Histórico-Jurídica Universidad Católica de Valparaíso, 1980); Aníbal Bascunán Valdés y Alamiro de Ávila Martel, Notas para el estudio de la Criminalidad y la Penología en Chile Colonial 16731818, (Santiago: Imprenta El Esfuerzo, 1941) y Marcello Carmagnani, El salariado minero en Chile Colonial. Su desarrollo en una sociedad provincial: el norte chico, 1690-1800 (Santiago: Editorial Universitaria, 1963).

24. Fernando Campos Harriet, Historia Constitucional de Chile (Santiago: Editorial Jurídica de Chile, 1956) y Julio Heise González, 150 años de evolución institucional (Santiago: Editorial Andrés Bello, 1996).

25. Ejemplo de ello, está en Mario Góngora del Campo y su Ensayohistórico sobre la noción de Estado en Chile en los siglos XIX y XX (Santiago: Editorial La Ciudad, 1981).

26. Marcelo Neira Navarro, «...Palo y Bizcochuelo... Ideología y disciplinamiento. Santiago primera mitad del siglo XIX» (Tesis Magister, Pontificia Universidad Católica de Valparaíso. 1998) 15. Véase también del mismo autor, «Castigo femenino en Chile durante la primera mitad del siglo XIX», Revista Historia no 37 (2004). 
El trabajo de Neira proporciona y refresca la información sobre esta primera mitad del siglo XIX chileno, adjuntando un copioso dossier de información y alcances acerca del sistema penal, administrativo, político, entre otros tópicos de envergadura histórica.

Por otra parte, deben destacarse las investigaciones de Marco Antonio León León, quien analiza el período 1810 y $1860^{27}$ y señala elementos acerca del nuevo orden institucional republicano, el cual debía apoyarse, en un orden social y una organización política-económica. En este escenario, quedaba claro que el gobierno y la élite gobernante debían tener como prioridad la administración de justicia y la educación, por tal razón:

mientras la primera -administración de justicia- era concebida como una voluntad constante y perpetua de dar a cada uno lo que le pertenecía, e implicaba la penalización o castigo público de los delitos, la segunda -la educación- se entendía como un valor necesario para sustentar dicho orden institucional y social. En este sentido, ambos eran complementarios. ${ }^{28}$

Por otra parte, la aceptación de un nuevo orden, frente al pasado colonial, fue un lento proceso que puso énfasis en la noción de cambio gradual, para evitar que se produjese cierto descontrol. Sin embargo, debe tenerse en cuenta que el concepto de orden se va a recuperar luego de consolidar la institucionalidad rota por los sucesos de Lircay en 1830, que significó el fin de la República Liberal, posterior a la emancipación y el nacimiento de la República Conservadora en Chile. La confianza se va a convertir en el tiempo cercano, en una relación directa con el orden impuesto. Esto provocó transformaciones desde aquí en adelante y que, en palabras de Ana María Steven, el miedo a la anarquía provocó un temor en la clase gobernante y rechazo a los procesos que traerían consigo cambios ${ }^{29}$. Al respecto, es importante señalar que las ideas, prejuicios y preocupaciones de Portales, en relación con los grupos marginados, van a ir adquiriendo una mayor presencia y protagonismo público, Además, a partir de la década de 1830. no van a ser distintas a ciertas prácticas del pasado en materia de criminalidad ${ }^{30}$, aunque las palabras del Ministro del Interior sobre que la República Liberal -que entregaba libertades y participación ciudadana-, llegara cuando se hubiera moralizado a la población, ${ }^{31}$ Primero que nada.

\section{Período 1850-1900}

Este período se va a caracterizar por la convergencia de una serie de hechos territoriales, políticos, económicos y sociales que van a producir transformaciones en todos los ámbitos de la vida nacional. Por cierto, esta etapa, en relación con la anterior, va a significar una nueva visión del fenómeno social y criminal.

27. Marco Antonio León León, «Las ideas sobre la ley y el pueblo en la construcción y consolidación de la República Chilena. 1810-1860», Revista Historia Crítica n 36 (2008): 82-101.

28. Marcos Antonio Léon León, «las ideas sobre la ley y...», 87.

29. Ana María Stuven, La seducción de un orden. Las elites y la construcción de Chile en las polémicas culturales y políticas del siglo XIX (Santiago: Ediciones de la Universidad Católica de Chile, 2000).

30. Alessandro Monteverde Sánchez y Juan Guillermo Estay Sepúlveda. «El sistema carcelario en Valparaíso 18361842. Los carros y presidios ambulantes según fuentes documentales». Revista Diálogos, $n^{\circ} 2$ (2013):145-165, doi: http://dx.doi.org/10.15517/dre.v14i2.11395.

31. Alejandro Concha y Julio Maltes. Historia de Chile. (Santiago: Editorial Bibliografía Internacional S.A., 1996. En el texto se pasa revista a la historia General de Chile, con énfasis en su historia institucional. 
Mandiola $\mathrm{Grecco}^{32}$ propone tres direcciones principales: la violencia colectiva -cuyo estudio añade una dimensión a la historia de los conflictos-, las revueltas y las revoluciones; la violencia cotidiana, a la manera de la antropología social y finalmente la violencia como criminalidad y represión, que entronca una historia renovada de la justicia y del derecho. Víctor Brangier ${ }^{33}$ realiza una propuesta investigativa, donde focaliza su estudio en el sistema penitenciario y las distintas reformas, para encontrar allí los pilares de una particular antropología criminal.

Por otro lado, se encuentra la visión sobre la criminalidad durante la segunda mitad del siglo XIX. No ha sido rigurosamente investigada y analizada. Asimismo, llama la atención el modo en que la observación de una institución -como los juzgados del crimen-, cuya documentación legada en el archivo está atravesada por una conciencia oficial sobre el sujeto procesado, ${ }^{34}$ ha estado ajeno al análisis de la producción decimonónica de una antropología criminal.

Esto último es, sin duda, un alcance realmente importante y que se relaciona con muchas investigaciones generadas en los últimos años, las cuales han replanteado la necesidad del uso, como un medio fundamental de investigación de las fuentes documentales judiciale $\mathrm{s}^{35} \mathrm{y}$ los distintos archivos criminales, sumados a todo tipo de actas, testamento y otros $^{36}$. Por otra parte, y retomando enfoques más generales de la historiografía nacional, Sergio Villalobos ${ }^{37}$ expresa que una parte importante del bajo pueblo llevaba una vida vagabunda, permitida por las facilidades de la alimentación y los miles de oportunidades de robar, sin ser castigados ni sorprendidos. Todo esto fue producto de la falta de estabilidad en el trabajo y, por consiguiente, una permanencia regular en las distintas localidades. Con todo ello, era fácil infringir las normas legales y morales de la sociedad, creándose un ambiente de irresponsabilidad. Los individuos seguían sus propias inclinaciones y ambiciones, sin que el control social pudiese encauzar su conducta.

Por su parte, Gonzalo Vial Correa ${ }^{38}$ señala que los contemporáneos sostenían que en el cambio de siglo se presenciaba un fuerte aumento de la delincuencia, sobre todo

32. Diego Mandiola Grecco. «¿Reprimir o rehabilitar? La razón y el castigo como espacio de representación cultural. 1857-1862» (Tesis para optar al Grado de Magister, Universidad Católica de Valparaíso, 2007).

33. Víctor Mauricio Brangier, «La fragilidad de la simbiosis médico-judicial y la producción de una antropología criminal. Juzgados del Crimen de Santiago, 1874-1906» (Tesis para optar al Grado de Magister, Universidad de Chile, 2008).

34. Brangier, «La fragilidad de la simbiosis», 16.

35. Manuel Salvat Monguillot, Los prontuarios jurídicos chilenos en la primera mitad del siglo XIX (Santiago: Andrés Bello, 1973).

36. Al respecto Ricardo Córdoba de la Llave, El homicidio en Andalucía a fines de la Edad Media. (Granada: Editorial Universidad de Granada, 2007); Iñaki Bazan Díaz, La historia social de las mentalidades y la criminalidad, en Historia a Debate, Tomo II (La Coruña: Editorial de la Universidad de Santiago de Compostela, 1995); Doris Moreno Martínez y José Luis Betrán Justicia criminal y criminalidad en la Cataluña Moderna: estudios y perspectivas de investigación (La Coruña: Editorial de la Universidad de Santiago de Compostela, 1995), Lila Caimari. Apenas un delincuente. Crimen, castigo y cultura en Argentina. 1880-1955 (Buenos Aires: Editorial Siglo XXI, 2004) y Eugenia Scarzanella Ni gringos Ni indios. Inmigración, criminalidad y racismo en Argentina. 1890-1940, (Buenos Aires: Ediciones Universidad Nacional de Quilmes, 1999).

37. Sergio Villalobos y otros, Historia de Chile (Santiago: Editorial Universitaria, 1979).

38. Gonzalo Vial Correa, Historia de Chile (1891-1973) (Santiago: Editorial Santillana, 1984). 
en las zonas rurales ${ }^{39}$. Se acota que la delincuencia urbana se incrementaba debido a las condiciones vitales -aislados, marginados- de los sectores populares, pero el país no supo responder ante las necesidades policiales, judiciales y carcelarias, producto del aumento de la población delincuente. La policía, entregada a las municipalidades, eran corruptas e ineficientes. Los juzgados se tornaron insuficientes para el inmenso movimiento penal. Pero, las críticas recogidas tienen un carácter muy significativo, cuando se ahonda la distancia entre el pueblo y el derecho, nacida mediado el siglo XIX, con un Código Civil europeizado. Además, suponía un desarrollo cultural no alcanzado por las masas. Dichas costumbres no cambiarán en los inicios del siglo XX, y se observa que el trato recibido por el bajo pueblo y la élite es distinto ante un mismo delito ${ }^{40}$.

Juan Cáceres ${ }^{41}$ presentó la relación que se desarrolla entre delito y crecimiento económico en la parte final del siglo XIX en Santiago. En su estudio, señala que si bien la modernidad urbana de Santiago ${ }^{42}$ se hizo presente en ciertos elementos específicos, como obras públicas, no sucedió lo mismo con las relaciones sociales ${ }^{43}$ que estaban en un pie tradicional y, algunas veces, expresaban sus estados de ánimo a través de comportamientos agresivos, los cuales también se acrecentarán en el siglo $\mathrm{XX}^{44}$.

En un estudio de profunda realidad humana, Gabriel Salazar ${ }^{45}$ muestra el mundo infantil en un país donde ser guachoera el pan cotidiano de cada día. Esto provocaba que ese niño terminara su vida como gañán, labrador o delincuente o siendo mano de obra barata en alguna incipiente industria ${ }^{46}$. En otra obra, mostró la vida de los peonesgañanes, que incluso deben trabajar por un bajo salario o sin este pecunio ${ }^{47}$. Eran hombres que por encontrarse en el camino y sin ocupación -es decir sin una papeleta que atestiguase que tenía amo- se les consideraba un vagabundo, malviviente sin oficio y, por consiguiente, se le acosaba y se le perseguía ${ }^{48}$. Eran unos sospechosos de nacimiento. Este

39. Alessandro Monteverde Sánchez, Crimen y delincuencia en Aconcagua 1800-1850 (Valparaíso: Ediciones de la Facultad de Humanidades de la Universidad de Playa Ancha, 2008).

40. Juan Guillermo Estay Sepúlveda, «El terremoto del 16 de agosto de 1906 en el interior de la región de Valparaíso» (Tesis de grado, Universidad de Playa Ancha, 2002). El autor pasa revista con documentos archivísticos inéditos los robos producidos por la élite a causa del terremoto que asoló la zona central de Chile y donde las personas acomodadas conocidas como "de cuello alto», no eran juzgadas por la policía y los tribunales de justicia, en cambio, el bajo pueblo, sufrió incluso fusilamiento en el acto, sin juicio alguno.

41. Juan Cáceres Muñoz, "Crecimiento económico, delitos y delincuencia en una sociedad en transformación: Santiago en la segunda mitad del sigloXX», Revista de Historia de las Mentalidades, $n^{\circ} 4$, (2000). Véase también del mismo autor Poder rural y estructura social, Colchagua, 1760-1860 (Santiago: Instituto de Historia Pontificia Universidad Católica de Valparaíso, 2007).

42. Luis Alberto Romero, «Urbanización y sectores populares: Santiago de Chile, 1830-1875», Revista de Estudios Urbanos y Regionales, $\mathrm{n}^{\circ} 31$ (1984).

43. Armando De Ramón Folch, «Estudio de una periferia urbano: Santiago de Chile 1850-1900», Revista Historia $n^{\circ}$ 20 (1985).

44. Instituto Nacional de Estadística, INE. Anuarios de Justicia. Estadísticas de Chile en el siglo XX 1900-1990. (Santiago: Impresión La nación, 1999).

45. Gabriel Salazar Vergara, Ser niño Guacho en la Historia de Chile (Santiago: Editorial Sur, 1990).

46. Jorge Rojas Flores, Los niños cristaleros: Trabajo infantil de la industria. Chile, 1880-1950 (Santiago, Dirección de Bibliotecas, Archivos y Museos DIBAM, 1996). Del mismo autor, Historia de la Infancia en el Chile Republicano (Santiago: Editorial Ocho Libros, 2010).

47. Gabriel Salazar Vergara, Labradores, peones y proletario (Santiago: Editorial Sur, 1985).

48. Alejandra Araya Espinoza, Ociosos, vagabundos y malentretenidos en Chile Colonial (Santiago: Dirección de Bibliotecas, Archivos y Museos DIBAM, 1999). 
vagabundo, que debía alimentarse, era presa fácil del bandidaje y del robo ${ }^{49}$. Construirían una marginación subjetiva de valores, costumbres, actitudes y conductas diferentes a las de los grupos integrados ${ }^{50}$. Estos personajes que deambulaban por el Chile rural ${ }^{51}$ no sólo rompían las normas sociales explícitas, sino también aquellas que devienen de lo que la élite consideraba como normal, correcto y adecuado. De igual modo, las mujeres se vieron muchas de ellas llevadas a la práctica de la prostitución ${ }^{52}$.

Estos grupos, que se organizaban posteriormente, iban a irrumpir en la sociedad a través de manifestaciones que más de algún dolor de cabeza provocarían en la élite gubernamental ${ }^{53}$. La élite solicitaría soluciones inmediatas a su falta de dignidad, que por ejemplo se veía en la salubridad, especialmente, en los sectores periféricos de las grandes urbes, sea esta la capital o el puerto de Valparaíso ${ }^{54}$ y que irán in crescendo con el inicio del nuevo siglo ${ }^{55}$.

Igor Goicovic, ${ }^{56}$ presentó un balance historiográfico preciso y adecuado, al señalar que mientras los clásicos de la historia social del país coinciden desde la formación de la República en adelante. es señera en transformaciones profundas, en aspectos institucionales y en la estructura económica del país. Los aspectos más controversiales han quedado prácticamente relegados a notas a pie de página y, cuando mucho, a algunos estudios referidos a coyunturas que tienden a explicarse por sí mismas. La violencia desplegada por los sin voz pone de manifiesto sus formas de relación con el Estado y con las élites dominantes, con las cuales estuvieron permanentemente en conflicto. En ese contexto, la expresión más radical de resistencia cultural fue el levantamiento social. Las características específicas de esta manifestación violenta corresponde a tres fenómenos clásicos: el motín urbano, el levantamiento minero y el bandolerismo rural.

Si bien los aportes en el campo de los estudios de la criminalidad se han incrementado, se cierra esta revisión, conscientes de que han quedado elementos importantes para el análisis de futuras revisiones historiográficas acerca de la criminalidad, los cuales entregaran nuevas luces para la comprensión de este flagelo.

49. Daniel Palma Alvarado, Ladrones: Historia social y cultural del robo en Chile, 1870-1920 (Santiago: Editorial Lom, 2011).

50. Jaime Valenzuela Márquez, Bandidaje rural en Chile central. Curicó, 1850-1900, (Santiago: Dirección de Bibliotecas, Archivos y Museos DIBAM, 1991).

51. Arnold J. Bauer, Lasociedad rural chilena. Desde la conquista española a nuestros días (Santiago: Editorial Andrés Bello, 1994).

52. Álvaro Góngora Escobedo, La prostitución en Santiago, 1813-1931: visión de las élites (Santiago: Editorial Andrés Bello, 1994).

53. Sergio Grez Tosso, De la 'regeneración del pueblo' a la huelga general. Génesis y evolución histórica del movimiento popular en Chile (1810-1890) (Santiago: Dirección de Bibliotecas, Archivos y Museos DIBAM, 1997).

54. Juan Guillermo Estay Sepúlveda y Alessandro Monteverde Sánchez, «Pestes en Chile: Viruela y bubónica a finales del siglo XIX y principios del XX», Revista Belize Journal of Medicine, $n^{\circ} 2$ (2015): 3-7.

55. Juan Guillermo Estay Sepúlveda y Felipe Vergara Lasnibat, «Salubridad en la provincia de Quillota 1900-1910. Notas para la historia de la Medicina a principios del siglo XX en los Departamentos de Quillota y Limache», en Quintas Jornadas de Historia de la Medicina de la Academia Chilena de la Medicina (Santiago: Editorial LOM, 2002).

56. Igor Goicovic. "Consideraciones teóricas sobre la violencia Social en Chile», Revista Última Década, $n^{\circ} 21$, (2004): 121-145. 


\section{Conclusiones}

La historia de la criminalidad se está construyendo por parte de los historiadores de Chile. Los esfuerzos han sido plausibles y las nuevas generaciones de historiadores deben sumergirse en los archivos para encontrar nuevas miradas y nuevas interpretaciones. Al mismo tiempo, hacer nuevas lecturas de los historiadores del siglo XIX y XX, que trabajaron la temática y adecuarlas -si Clío lo permite- a nuevas disciplinas auxiliares y puntos de vista. Sin embargo, no se puede dejar de lado, que debe efectuarse este análisis a la luz del tiempo y el espacio donde ocurrió sin juzgar, sino comprender.

\section{ABSTRACT}

\section{Criminality as a Historiographic Topic: Chile in the XIX century}

The problem of criminology has been investigated by diverse historians through time; however, it has faced a lack of answers, studies of general events or related topics have come to replace this shortage. A discussion to fulfill this vacancy with significant works is presented; which by being analyzed partly covers that lack information and help with the understanding of individual works from some researchers who have systematize a predicament. It is about a present, recurring and discursive problem; which is constantly covered by new and valuable interpretations. By analyzing the work of historians who have developed the topic of criminality and criminology, we want to contribute considerably to disclose new interpretations and create new knowledge.

Key words: criminality- elite- Chile - social control - XIX century.

\section{RÉSUMÉ}

La criminalité comme sujet historiographique : Le Chili dans le XIX ${ }^{\text {ème }}$ siècle La problématique de la criminologie a été étudiée par divers historiens à travers le temps. Cependant, il y a un manque de réponses lequel est comblé par des études générales des événements et approximations thématiques. Cet article tente de remplir ce vide avec l'analyse de travaux significatifs afin de couvrir ce déficit, et de comprendre le travail individuel de plusieurs investigateurs qui ont systématisé une problématique très fréquente et discursive de l'actualité. Il s'agit de la criminalité et la criminologie ; cette thématique est couverte de nouvelles et précieuses interprétations. Par le via de l'analyse des œuvres des historiens qui ont abordé cette thématique, on veut contribuer en donnant des nouvelles interprétations pour accroître l'ensemble de connaissances.

Mots-clés: Criminalité, élites, Chili, contrôle social, XIX ${ }^{\text {ème }}$ siècle.

\section{Bibliografía}

Álvarez Uría, Fernando. Miserables y Locos. Madrid: Editorial Tusquets, 1983.

Araya Espinoza, Alejandra. Ociosos, vagabundos y malentretenidos en Chile Colonial. Santiago: Dirección de Bibliotecas, Archivos y Museos DIBAM, 1999.

Barros Arena, Diego. Historia General de Chile, Vol. VI. Santiago: Editorial Nascimento, 1932.

Bazan Díaz, Iñaki. La historia social de las mentalidades y la criminalidad, en Historia a Debate, Tomo II. La Coruña: Editorial de la Universidad de Santiago de Compostela, 1995. 
Brangier, Víctor Mauricio. «La fragilidad de la simbiosis médico-judicial y la producción de una antropología criminal. Juzgados del Crimen de Santiago, 1874-1906». Tesis para optar al Grado de Magister. Universidad de Chile, 2008.

Basave Fernández del Valle, Agustín. Meditación sobre lapena de muerte. México: Editorial Fondo de Cultura Económica, 1997.

Bascuñán Valdés, Aníbal y De Ávila Martel Alamiro. Notas para el estudio de la Criminalidad y la Penología en Chile Colonial 1673-1818. Santiago: Imprenta El Esfuerzo, 1941.

Bauer, Arnold J. Lasociedad rural chilena. Desde la conquista española a nuestros días. Santiago: Editorial Andrés Bello, 1994.

Beccaria, Cesare. De los delitos y de las penas. Madrid: Alianza Editorial, 1968.

Campos Harriet, Fernando. Historia Constitucional de Chile. Santiago: Editorial Jurídica de Chile, 1956.

Cáceres Muñoz, Juan. «Crecimiento económico, delitos y delincuencia en una sociedad en transformación: Santiago en la segunda mitad del siglo X». Revista de Historia de las Mentalidades, $\mathrm{n}^{\circ}$ 4. (2000).

Cáceres Muñoz, Juan. Poder rural y estructura social, Colchagua, 1760-1860. Santiago: Instituto de Historia Pontificia Universidad Católica de Valparaíso, 2007.

Caimari, Lila. Apenas un delincuente. Crimen, castigo y cultura en Argentina. 1880-1955. Buenos Aires: Editorial Siglo XXI, 2004.

Carmagnani, Marcello. El otro Occidente. México: Editorial Fondo de Cultura Económica/El Colegio de México, 2004

Carmagnani, Marcello. El salariado minero en Chile Colonial. Su desarrollo en una sociedad provincial: el norte chico, 1690-1800. Santiago: Editorial Universitaria, 1963.

Castan, Nicole. Justice et repression en Languedoc a l'epoque des Lumieres. Paris: Editorial Llamerion, 1980.

Chiaramente, José y Souto, Nora. De la ciudad a la nación. Las vicisitudes de la organización política Argentina y los fundamentos de la conciencia nacional, en Relatos de nación. La construcción de las identidades nacionales en el mundo hispánico Tomo I. Madrid: Instituto de Filosofía Consejo Superior de Investigaciones Científicas/Organización de Estados Americanos para la Educación, la Ciencia y la Cultura, 2005.

Christie, Nils. Christie. Los límites del Dolor. México: Editorial Fondo de Cultura Económica, 1984.

Chust Caleno, Miguel. Lacoyuntura de la crisis: España, América, en Historia General de América Latina. Madrid: Editorial UNESCO/Editorial Trotta, Tomo V, 2003.

Cobos, María Teresa. «La Institución del Juez del Campo en el reino de Chile durante el siglo XVIII». Revista Histórico-Jurídica Universidad Católica de Valparaíso, (1980).

Collier, Simon y Sater, William. Historia de Chile 1808-1994. Madrid: Cambridge University Press, 1999.

Concha, Alejandro y Maltes, Julio. Historia de Chile. Santiago: Editorial Bibliografía Internacional S.A., 1996.

Contreras, Carlos y Cueto, Marcos. Historia del Perú Contemporáneo. Lima: Red para el Desarrollo de las Ciencias Sociales en el Perú, 2000.

Córdoba de la Llave, Ricardo. El homicidio en Andalucía a fines de la Edad Media. Granada: Editorial Universidad de Granada, 2007.

De Ramon Folch, Armando. «Estudio de una periferia urbano: Santiago de Chile 1850-1900». Revista Historia $n^{\circ} 20$ (1985).

De Rivacoba, Manuel. Violencia y Justicia. Valparaíso: Editorial Universidad de Valparaíso, 2002. 
Del Olmo, Rosa. América Latina y su criminología. México: Editorial Siglo XXI, 1987.

Di Liscia, Maria Silvia y Bohoslavsky, Ernesto. Instituciones y formas de control social en AméricaLatina, 18401940. Una revisión. Buenos Aires: Prometeo Libros, 2005.

Di Simplico, Oscar. La criminalitáa Siena. (1551-1808). Bolonia: Quaderni Storici N 49, Editorial Il Molino, 1982.

Edwards Bello, Joaquín. Andando por Madrid y otras páginas. Santiago: Editorial Andrés Bello, 1969.

Encina, Francisco Antonio. Historia de Chile, Vol. XX. Santiago: Editorial Nascimento, 1947.

Estay Sepúlveda, Juan Guillermo. «El terremoto del 16 de agosto de 1906 en el interior de la Región de Valparaíso». Tesis de grado. Universidad de Playa Ancha, 2002.

Estay Sepúlveda, Juan Guillermo y Vergara Lasnibat, Felipe. «Salubridad en la provincia de Quillota 1900-1910. Notas para la historia de la Medicina a principios del siglo XX en los Departamentos de Quillota y Limache», en Quintas Jornadas de Historia de la Medicina de la Academia Chilena de la Medicina. Santiago: Editorial LOM, 2002.

Estay Sepúlveda, Juan Guillermo y Alessandro Monteverde Sánchez. «Pestes en Chile: viruela y bubónica a finales del siglo XIX y principios del XX». Revista Belize Journal of Medicine. n 2 (2015). 3-7.

Eyzaguirre, Jaime. Historia de Chile. Santiago: Editorial Zig-Zag, 1982.

Foucault, Michael. Sorvegliare e punire. Nascita della prigione. Torino: Editorial Giulio Einaudi Editores, 1976.

Foucault, Michel. La vida de los hombres infames. Buenos Aires: Editorial Altamira, 1996.

Galdámes, Luis. Historia de Chile. Santiago: Editorial Zig-Zag, 1952.

Gil Villa, Fernando. La delincuencia y su circunstancia: sociología del crimen y la desviación. Valencia: Editorial Tirant lo Blanch, 2004

Goicovic, Igor. «Consideraciones teóricas sobre la violencia Social en Chile». Revista Última Década, $\mathrm{n}^{\circ} 21$ (2004).

Góngora del Campo, Mario. Vagabundaje y Sociedad Fronteriza. Valparaíso: Editorial Jurídica Universidad Católica de Valparaíso, 1980.

Góngora del Campo, Mario. Ensayo histórico sobre la noción de Estado en Chile en los siglos XIX y XX. Santiago: Editorial La Ciudad, 1981.

Góngora Escobedo, Álvaro. La prostitución en Santiago, 1813-1931: visión de las élites. Santiago: Editorial Andrés Bello, 1994.

Grez Tosso, Sergio, De la 'regeneración del pueblo' a la huelga general. Génesis y evolución histórica del movimiento popular en Chile (1810-1890). Santiago: Dirección de Bibliotecas, Archivos y Museos DIBAM, 1997.

Halperin Donghi, Tulio (compilador). El ocaso del ordenColonial en Hispanoamérica (Buenos Aires: Editorial Sudamericana, 1978.

Heise González, Julio. 150 años de evolución institucional. Santiago: Editorial Andrés Bello, 1996.

Hobsbawm, Eric, I Rebelli. Forme primitive di rivoltasociale. Torino: Giulio Einaudi Editores, 1974.

Hobsbawm, Eric, I banditi. Il bantitismo social en ell' etá modern. Torino: Giulio Enaudi Editores, 1971.

Imbert, Jean. La Pena de Muerte. México: Editorial Fondo de Cultura Económica, 1993.

Instituto Nacional de Estadística, INE. Anuarios de Justicia. Estadísticas de Chile en el siglo XX 1900-1990. Santiago: Impresión La nación, 1999. 
León León, Marco Antonio. «Las ideas sobre la ley y el pueblo en la construcción y consolidación de la República Chilena. 1810-1860». Revista Historia Crítica ${ }^{\circ} 36$ (2008).

Levra, Umberto. La scienza e la colpa. Crimini, criminali, criminología. Un voltodell' ottocento. Milano: Editorial Electra, 1985.

Lombardi, John V. Independenciay esclavitud en el periodode transición de 1750-1850 en Historia General de América Latina. Madrid: Editorial UNESCO/Editorial Trotta, Tomo V, 2003.

López-Rey y Arrojo, Manuel. La criminalidad. Un estudio analitico. Madrid: Editorial Tecnos, 1976.

López-Rey y Arrojo, Manuel. Las dimensiones de la Criminalidad. Córdoba: Editorial Marcos Lerner, 1987.

Lorenzo Schiffino, Santiago. Origen de las Ciudades Chilenas. Las fundaciones del siglo XVIII. Santiago: Editorial Andrés Bello, 1983.

Lozano Armendares, Teresa. La Criminalidad en la Ciudad de México, 1800-1821. México: Universidad Nacional Autónoma de México, 1987.

Lynch, John. Los factores estructurales de la crisis: la crisis del orden Colonial, en Historia General de América Latina. Madrid: Editorial UNESCO/Editorial Trotta, Tomo V, 2003.

Lynch, John. América Latina entre la Colonia y Nación. Barcelona: Editorial Crítica, 2001.

Lynch, John. LasRevoluciones Hispanoamericanas 1808-1826. Barcelona: Editorial Ariel, 2010.

Malinowski, Bronislaw. Crimen y costumbre en la sociedad salvaje. Barcelona: Editorial Ariel, 1971.

Mandiola Grecco, Diego. «¿Reprimir o rehabilitar? La razón y el castigo como espacio de representación cultural. 1857-1862». Tesis para optar al Grado de Magister. Universidad Católica de Valparaíso, 2007.

Manríquez, Nelson. Las sociedades originarias en el ámbito de la formulación inicial de los proyectos nacionales como culminación de los procesos de continuidad y ruptura, en Historia General de América Latina. Madrid: Editorial UNESCO/Editorial Trotta, Tomo V, 2003.

Medina, José Toribio. Cosas de la Colonia. Aportes para la crónica del siglo XVIII en Chile. Santiago: Fondo Histórico y Bibliográfico José Toribio Medina, 1952.

Mollo, Juan Pablo. Psicoanálisis y criminología. Estudios sobre la delincuencia. Buenos Aires: Editorial Paidos, 2010.

Monteverde Sánchez, Alessandro. Crimen y delincuencia en Aconcagua 1800-1850. Valparaíso: Ediciones de la Facultad de Humanidades de la Universidad de Playa Ancha, 2008.

Monteverde Sánchez, Alessandro y Estay Sepúlveda, Juan Guillermo. «El sistema carcelario en Valparaíso 1836-1842. Los carros y presidios ambulantes según fuentes documentales». Revista Diálogos, $n^{\circ} 2$, (2013): 145-165. doi http://dx.doi.org/10.15517/dre.v14i2.11395

Moreno Martínez, Doris y Betrán, José Luis. Justicia criminal y criminalidad en la Cataluña Moderna: estudios y perspectivas de investigación. La Coruña: Editorial de la Universidad de Santiago de Compostela, 1995.

Neira Navarro, Marcelo «...Palo y Bizcochuelo... Ideología y disciplinamiento. Santiago primera mitad del siglo XIX». Tesis Magister. Pontificia Universidad Católica de Valparaíso., 1998.

Neira Navarro, Marcelo. «Castigo femenino en Chile durante la primera mitad del siglo XIX». Revista Historia, $n^{o} 37,2004$.

Palma Alvarado, Daniel. Ladrones: Historia social y cultural del robo en Chile, 1870-1920. Santiago: Editorial Lom, 2011.

Pavarini, Massimo. Control y dominación: Teorías criminológicasburguesas y proyecto hegemónico. México: Editorial Siglo XXI, 2003. 
Peset, José Luis. Ciencia y marginación. Madrid: Editorial Crítica, 1983.

Quinney, Richard. Clases, Estado yDelincuencia. México: Editorial Fondo de Cultura Económica, 1985.

Rico, José María. Crimen y justicia en América Latina. México: Editorial Siglo XXI, 1981.

Rojas Flores, Jorge. Los niños cristaleros: Trabajo infantil de la industria. Chile, 1880-1950. Santiago, Dirección de Bibliotecas, Archivos y Museos DIBAM, 1996.

Rojas Flores, Jorge. Historia de la Infancia en el Chile Republicano. Santiago: Editorial Ocho Libros, 2010.

Romero, José Luis. Independenza en Storiadell’ America Latina. Firenze: La Nuova Italia Editrize, 1979.

Romero, Luis Alberto, «Urbanización y sectores populares: Santiago de Chile, 1830-1875». Revista de Estudios Urbanos y Regionales. volumen XI, No 31. Santiago: Pontificia Universidad Católica de Chile, 1984.

Sábato, Hilda. Ciudadanía Política y Formación de naciones. Perspectivas históricas de América Latina (México: Editorial Fondo de Cultura Económica/El Colegio de México, 1999.

Salazar Vergara, Gabriel. Ser niño Guacho en la Historia de Chile. Santiago: Editorial Sur, 1990.

Salazar Vergara, Gabriel. Labradores, peones y proletario. Santiago: Editorial Sur, 1985.

Salvatore, Ricardo S. Subalternos, derechos y justicia penal. Barcelona: Editorial Gedisa S.A., 2010.

Salvat Monguillot, Manuel. Los prontuarios jurídicos chilenos en la primera mitad del siglo XIX. Santiago: Andrés Bello, 1973.

Scarzanella, Eugenia. Ni gringos Ni indios. Inmigración, criminalidad y racismo en Argentina. 1890-1940, Buenos Aires: Ediciones Universidad Nacional de Quilmes, 1999.

Serrano Maillo, Alfonso. Introducción a la criminología. Madrid: Editorial Dykinson, 2009.

Skidmore, Thomas E. y Smith, Peter H. Historia Contemporánea de América Latina Barcelona: Editorial Crítica, 1996.

Slemian, Andres y Pimenta, Joao Paulo. O Nascimento político do Brasil, as origen do Estado e da nacao (18081825). Río de Janeiro: DP\&A Editora,2003.

Stuven, Ana María. La seducción de un orden. Las elites y la construcción de Chile en las polémicas culturales y políticas del siglo XIX. Santiago: Ediciones de la Universidad Católica de Chile, 2000.

Sueiro, Daniel. La pena de muerte. Madrid: Alianza Editorial, 1974.

Taylor, William. "Algunos temas de la historia social de México en las Actas de juicios criminales». Revista Relaciones Estudios de Historia y Sociedad. Vol. III. Número 11, 1982. http:/letzakutarakua.colmich.edu. mx/relaciones/011/pdflWilliamTaylor.pdf, de fecha 09 de mayo de 2014.

Valenzuela Márquez, Jaime. Bandidaje rural en Chile central. Curicó, 1850-1900. Santiago: Dirección de Bibliotecas, Archivos y Museos DIBAM, 1991.

Vial Correa, Gonzalo. Historia de Chile (1891-1973). Santiago: Editorial Santillana, 1984.

Villalobos, Sergio y otros, Historia de Chile. Santiago: Editorial Universitaria, 1979.

Zehr, Howard. Crime and the development of modern society. Guildford: Editorial Biddles Ltd., 1976. 